\title{
Preliminary Study to Compare the Insertion/Removal Force of PEEK and Co-Cr Clasps
}

\author{
Sara Alvarez ${ }^{1, *}$, Tomas Escuin ${ }^{2}$, Rafael Claramunt ${ }^{3}$, Carlos Ascaso $^{4,5}$ \\ ${ }^{1}$ Dental Faculty, University of Barcelona, Spain \\ ${ }^{2}$ Department of Rehabilitation and Maxillofacial Prostheses, Faculty of Odontology, University of Barcelona, Spain \\ ${ }^{3}$ Polytechnic University of Madrid, Spain \\ ${ }^{4}$ (Biostatistics) of Medicine School, University of Barcelona, Unit of Epidemiology and Statistics Fundació Clínic, Spain \\ ${ }^{5}$ Department of Public Health, Faculty of Medicine, University of Barcelona, Spain
}

Copyright@2017 by authors, all rights reserved. Authors agree that this article remains permanently open access under the terms of the Creative Commons Attribution License 4.0 International License

\begin{abstract}
Introduction: The objective of this study in vitro was to evaluate the retentive forces of PEEK and $\mathrm{Co}-\mathrm{Cr}$ alloy clasps by the insertion and removal test simulating 10 years use. Material and Methods: 16 PEEK clasps and 16 Co-Cr clasps were fabricated for 32 third molars with similar dimensions. Each clasp assembly was subjected to an insertion /removal test on its abutment molar with a Test Universal Machine (Instron ${ }^{\circledR}$ 4465, Instron Co. Ltd, Norwwod, MA) to analyze with Newton the retention force. To analyze the retention over the course of insertion/removal test, retention was measured every 1500 cycles. With a total of 15000 cycles, which represents the insertion / removal of the clasp for 10 years, estimating that the patient would do four full cycles a day. Results: Co-Cr clasps showed higher retention (mean 13,63 Nw) than PEEK clasps (mean 8,04 $\mathrm{Nw}$ ). All clasps exhibited an increase in retentive force during the first period of cycling followed by continuous decrease. Were obtained significant differences between retention forces of each material groups $(p<0.001)$. Conclusions: We can use PEEK clasps for removable prostheses. Retention forces of PEEK clasps were clinically acceptable, but inferior retention forces of Co-Cr clasps. They are needed in vivo studies to contrast the results.
\end{abstract}

Keywords PEEK, Cobalt-Chromium Clasps, Insertion Force, Removable Partial Denture

\section{Introduction}

Different materials have been used to make clasps for removal prostheses, from cobalt-chromium, titanium and gold [9]. The clasps undergo a constant deformation due to the movements of the chewing and the removal of the prostheses [8]. The stress distribution on the clasp depends on the modulus of elasticity of the alloy. According et al., the gold clasps have a longer half-life compared to fatigue, while those of Ti-6Al-7Nb alloys show a better resistance to permanent deformation [7,16,21,31]. According

Kim et al, gold and Co-Cr clasps experience a gradual decrease of their retentive force on the tooth abutment [1].

In order for the clasps to be retentive they must be flexible and retain the prostheses satisfactorily $[12,13,15]$. They do not have to transmit excess stress to the abutment tooth. Previous studies have shown that clasps made of more elastic materials present better resistance to loss of retention $[3,1,29]$.

The retentive arms of the clasp must be flexible and capable of returning satisfactorily to their original shape, in order to retain the prostheses $[4,10,19,27,32]$.

On the other hand, if the clasps are excessively flexible, they may not provide adequate retention when positioned on the abutment tooth $[5,25,28]$.

The progressive loss of mechanical properties after repeated loads is an important consideration for the choice of materials $[2,11,20]$. Although, clasp fatigue is based on recurrent deflection by repeatedly inserting and removing the prostheses [8,24].

PEEK (polyetherketon) and PEKK (polyetherketonketon) are two polymers of the polyaryletherketone (PAEK) group, which is part of a relatively new family of high temperature thermoplastic polymers. These thermoplastics have great physical resistance, hydrological stability and rigidity, with a modulus of elasticity similar to bone. It is a main aromatic chain, connected with ketone and ether groups. In medicine, PAEK has been shown to be an excellent substitute for titanium in different therapeutic applications, and in dentistry as a temporary implant abutment $[6,17,18,3]$.

Previous studies have shown that clasps made with more elastic materials have greater resistance to loss of retention $[14,22,23]$.

The low modulus of elasticity of the thermoplastic resins presents superior flexibility compared to the conventional 
Cr-Co alloys [3,30,26].

\section{Objectives}

The objective of this in vitro study is to evaluate the retention force of the PEEK and Co-Cr clasps by a test that simulates the insertion and removal of the clasps for 10 years.

\section{Hypothesis}

The hypothesis of this study would be that after the simulation of the insertion / removal of the clasps, the Co-Cr clasps will present a retention force different from the PEEK clasps.

\section{Materials and Methods}

\section{Type of Study}

In vitro study, experimental design to compare the retention force of PEEK clasps and conventional $\mathrm{Cr}-\mathrm{Co}$ clasps.

\section{Calculation Sample Size}

The size of the sample was decided taking into account the previous works of Dong-Suk et al. of the year 2004 in which there was statistical power to show differences between $\mathrm{Ni}$-Ti, Cr-Co and type IV gold materials. The sample size was 16 individuals for group.

\section{Description of the Variables}

The response variables of the experiment will be; The Newtons necessary for clasp eviction every 1500 charge cycles between 0 and 15,000, the Newtons necessary for clasp eviction after the end of the aging cycle.

\section{Abutment Fabrication}

We will use as abutment natural teeth, 32 third molars of similar size and shape, 16 for Cr-Co clasps and 16 for PEEK clasps.

The inclusion criteria for molar selection were: third molars without any reconstruction or existing caries and similar crown dimensions $(8-10 \mathrm{~mm}$ mesio-distal sense, 6-8mm sense bucco-lingual, 6-8mm height crown). In turn, all third molars larger or smaller than the given figures and teeth with caries and / or reconstructions were excluded from the study.

These teeth are fixed on a self-curing resin base in an aluminum mold $30 \mathrm{~mm}$ in diameter and $30 \mathrm{~mm}$ high.

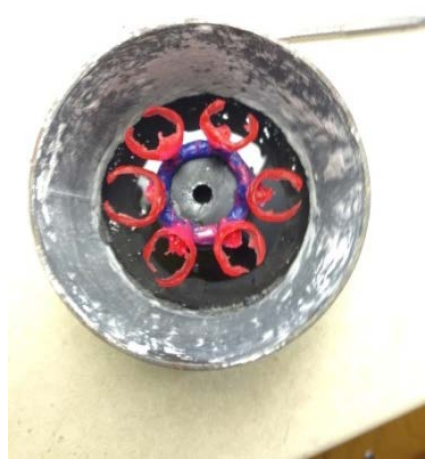

Figure 1. clasps design in calcinable pattern

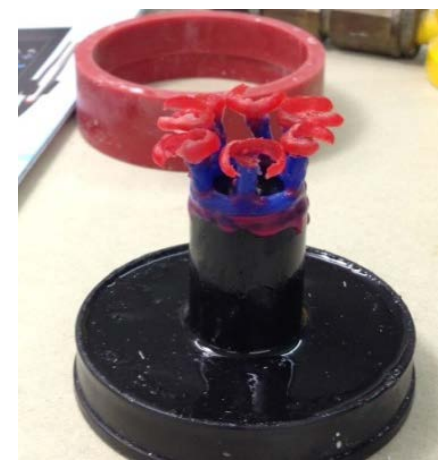

Figure 2. clasps prepared for the investment

\section{Co-Cr Clasp Fabrication}

As soon as we have the teeth embedded with resin in the base, we proceed to the removal of the retentive zone by means of a parallelizer for the design of the clasps (Figure 6, 7 and 8 ).

We proceed to the making of the clasps in resin, calcinable pattern resin with occlusal supports, retentive arm and reciprocal arm, designed as a clasp of type akers of thickness of $1 \mathrm{~mm} \times 1.5 \mathrm{~mm}$. We placed a $4 \mathrm{~mm}$ thick vertical sprue in the area of the occlusal support of the clasp that we helped to make the test later.

We cast in Co-Cr alloy clasps and trimmed them with 0.5 alumina micron particles at $0.25 \mathrm{MPa}$ pressure.

\section{Peek Clasp Fabrication}

Same as in Co-Cr clasps when we have the teeth embedded with resin in the base, we proceed to the removal of the retentive zone by means of a parallelizer for the design of the clasps (Figure 6, 7 and 8). We design them with calcinable pattern resin with occlusal supports, retentive arm and reciprocal arm. We also design a clasp type akers of thickness $1.5 \mathrm{~mm} \times 3 \mathrm{~mm}$ (Figure 1 and 2). These clasps should be thicker because of the properties of the material. We put a trough parallel to the insertion axis that will help us to do the test later.

The PEEK clasps were injected the resin with the Thermopress 400 machine from the Bredent house (Figure 3, 4 and 5). 


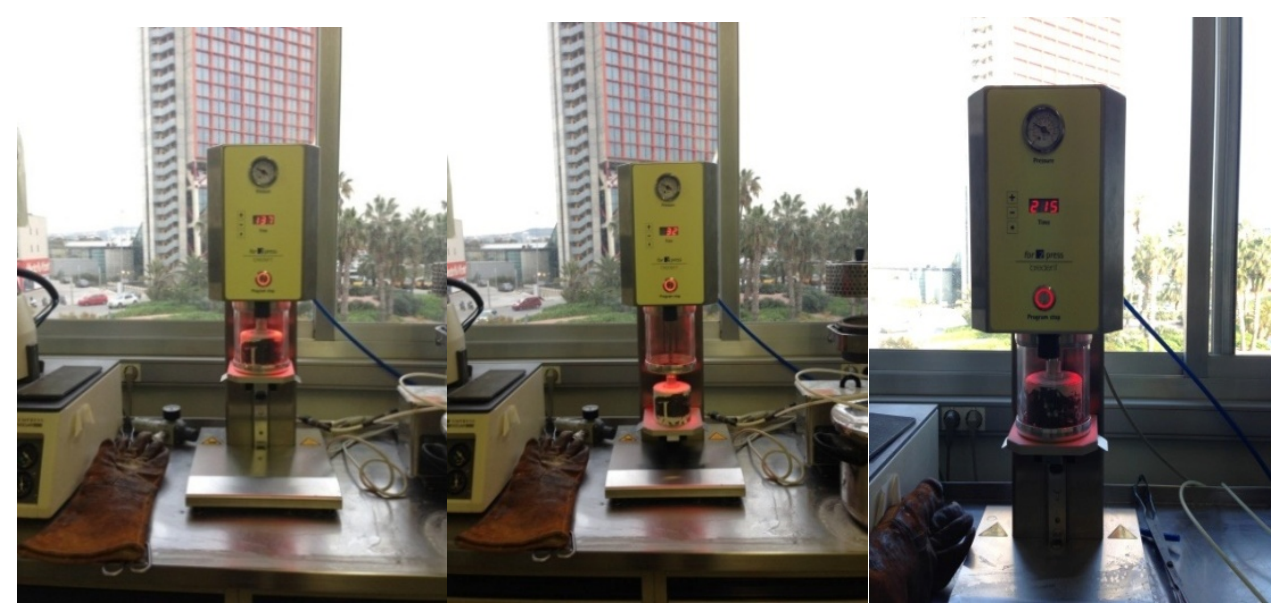

Figure 3, 4, 5. PEEK clasps were injected the resin with the Thermopress 400 machine from the Bredent

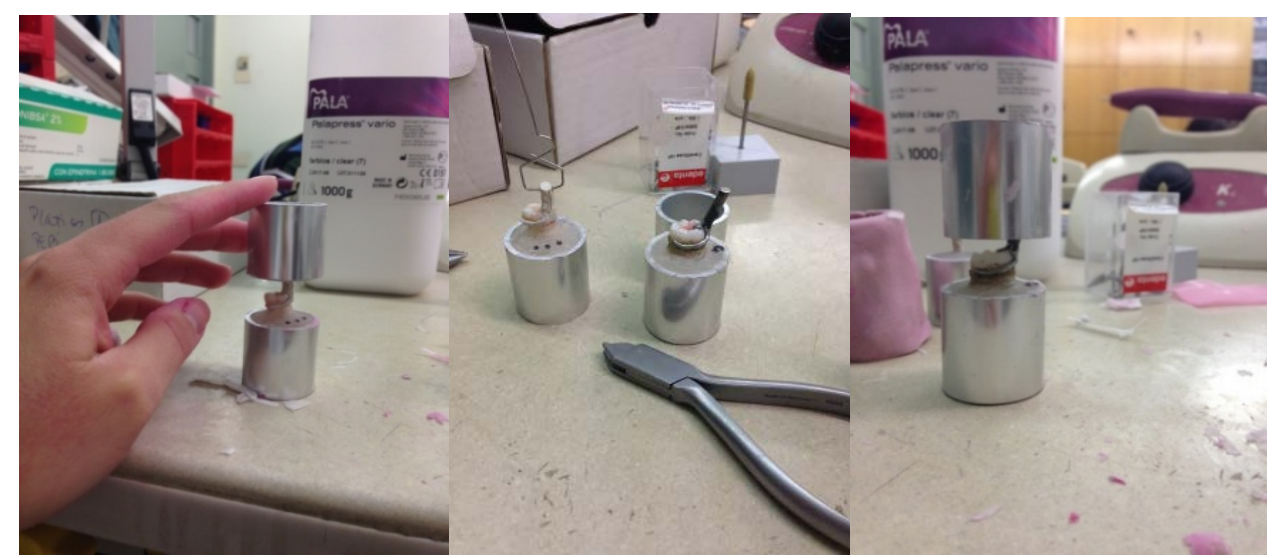

Figure 6, 7, 8. clasps of PEEK and Co-Cr fixed on a self-curing resin base in an aluminum mold $30 \mathrm{~mm}$ in diameter and $30 \mathrm{~mm}$ high

\section{Test Insertion / Removal of Clasps}

We will perform a procedure of aging of the clasp, we will proceed to the insertion and removal of the clasp in the abutment tooth. The clasps will be attached with an aluminum base and embedded with resin to the top of the machine with which we will perform the test (Instron ${ }^{\circledR} 4465$, Instron Co. Ltd, Norwwod, MA), so the insertion / removal of the clasp will continue a vertical path parallel to the guide planes of the abutment tooth (Figure 9 and10).

In order to measure Newton's force for the removal of the clasps we will use a universal test machine (Instron ${ }^{\circledR} 4465$, Instron Co. Ltd, Norwood, MA). With a speed of $8 \mathrm{~mm} / \mathrm{s}$ we will measure the force of retention of the clasp before beginning the process of aging.

The test machine it's like a masticatory simulator. To analyze the data, intervals 1500 cycles were established.

A total of 15000 cycles were performed, representing the simulated insertion and removal of the clasps over 10 years, estimating that the patient would perform four complete cycles per day.

Each interval established corresponds a 10 consecutive insertion and removal cycles.

We perform a measurement of the retention force of the clasps after each cycle, so as to study in Newton the decrease of the retention force over time.

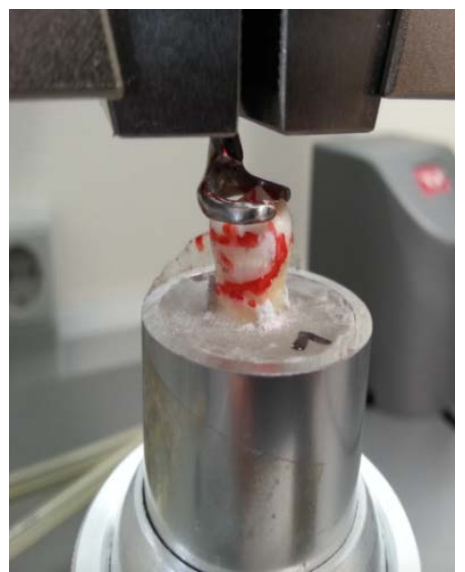

Figure 9. The clasps will be attached with an aluminum base and embedded with resin to the top of the machine with which we will perform the test (Instron ${ }^{\circledR} 4465$, Instron Co. Ltd, Norwwod, MA)

\section{Results}

To evaluate the strength of removal and insertion in relation to the number of cycles and the clasp material will be used models of covarianza analysis. The T. Student test for 
independent data will be used to evaluate the differences between the removal and insertion forces according to clasp materials after the aging process. The parameters estimates will be made with a Confidence Interval of 95\%. Hypothesis contrasts are evaluated with an alpha error of $5 \%$. Statistical analyzes are compared with the SPSS vs. 21 package.

The size of the sample was reduced after testing a clasp from each group, and observed that the forces of removal between the Co-Cr clasp and PEEK clasp were clearly different. Thus, it was decided to study 5 samples of the PEEK clasps and 15 samples of the Co-Ce clasps. More Co-Cr samples were tested as there were greater differences in retention force as the clasp was more or less fitted to the tooth.

In the results we have classified as material 1 the clasps of $\mathrm{Co}-\mathrm{Cr}$ and as material 2 the clasps of PEEK.

We have analyzed the Newtons (NW) of removal and insertion of each clasp subjected to the cycles.

\section{Removal Test}

In Diagram 1 and 2 the strength in NW required for the removal of the Co-Cr clasps (material 1) and the PEEK clasps (material 2) is represented by a dot diagram. In both the Cr-Co and PEEK clasp tests, we observe a clasp that reaches higher NW removal values.

Pearson's correlation coefficient in both material 1 and 2 shows the non-existent correlation between the cycles and the NW required for the removal of the clasps.

In Table 1 we observe an average of $13.63 \mathrm{NW}$ of force for the clasps of material 1 and a mean of $8.04 \mathrm{NW}$ for the clasps of material 2.

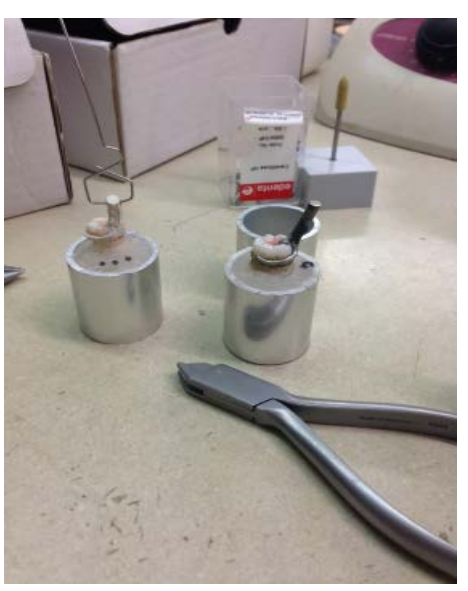

Figure 10. PEEK and Co-Cr clasps embedded on resin

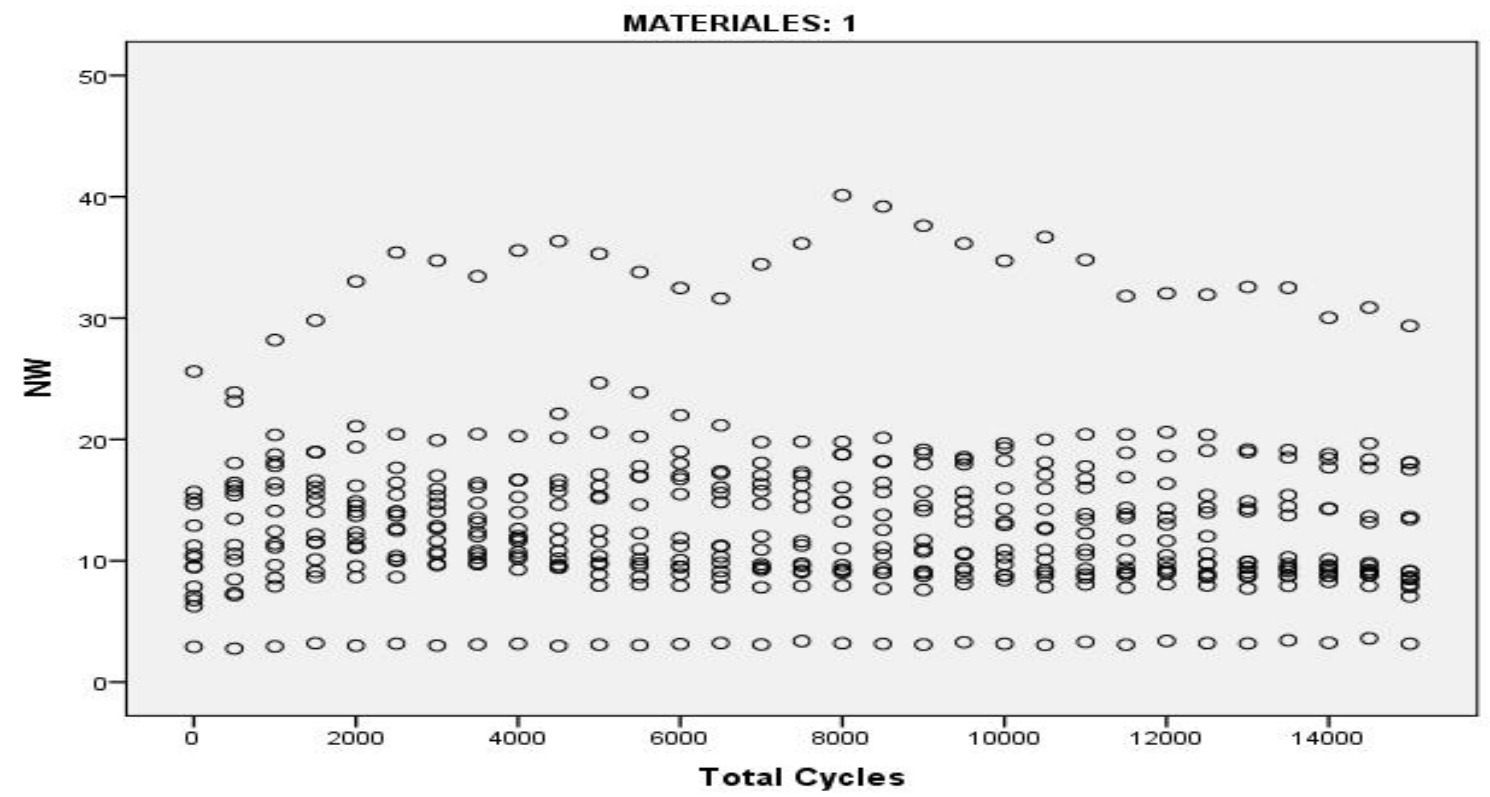




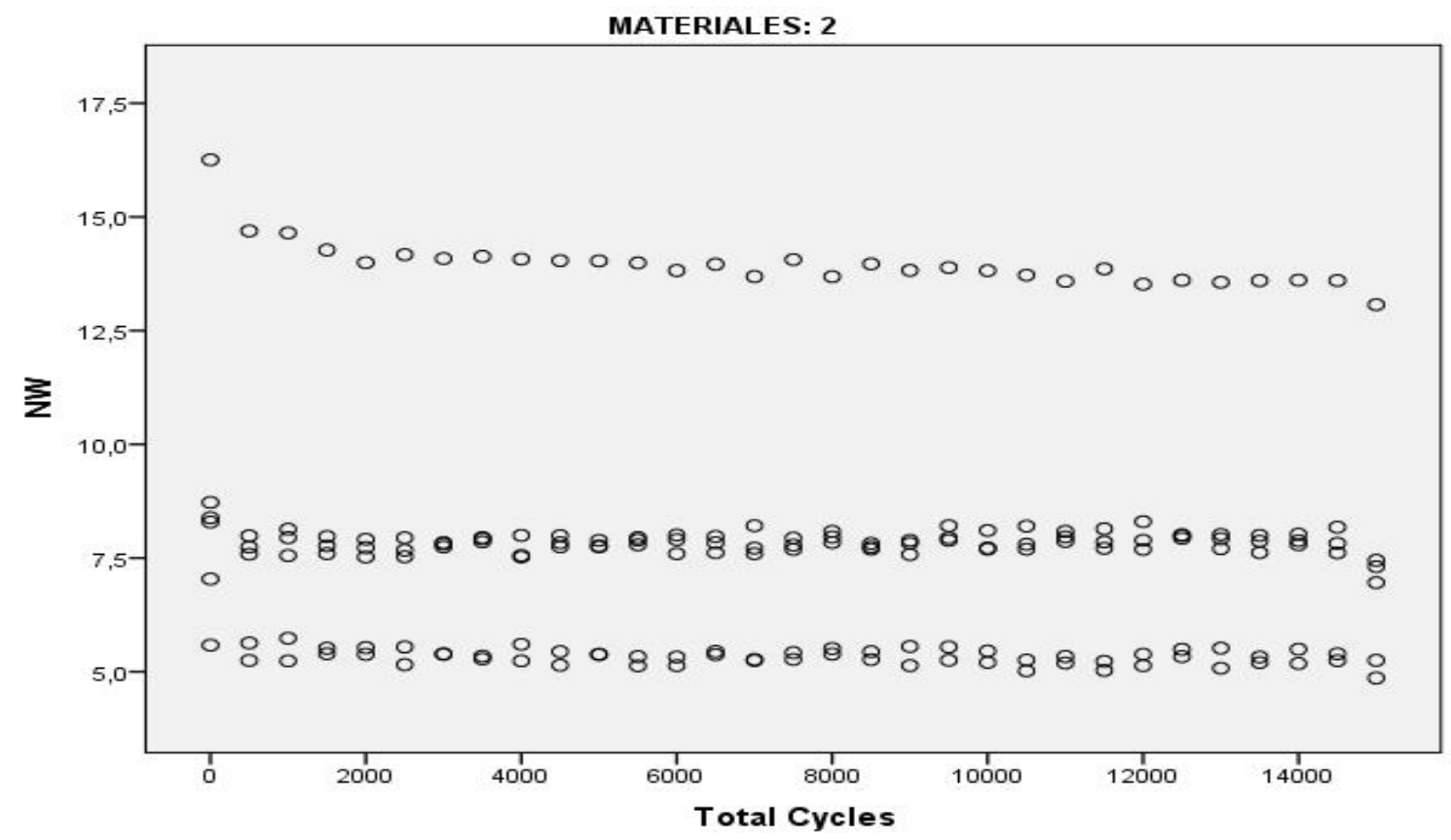

Diagram 1 - 2. $\quad$ dot diagram force in Nw required for desinsertion of the clasps of materials 1 and 2.

Table 1. means of desinsertion force of materials 1 and 2 .

\begin{tabular}{|c|c|c|c|r|}
\hline Materiales & N & Media & Desv. estándar & Media de error estándar \\
\hline NW 1 & 465 & 13.63 & 6,907 &, 320 \\
2 & 186 & 8,04 & 2,899 &, 213 \\
\hline
\end{tabular}

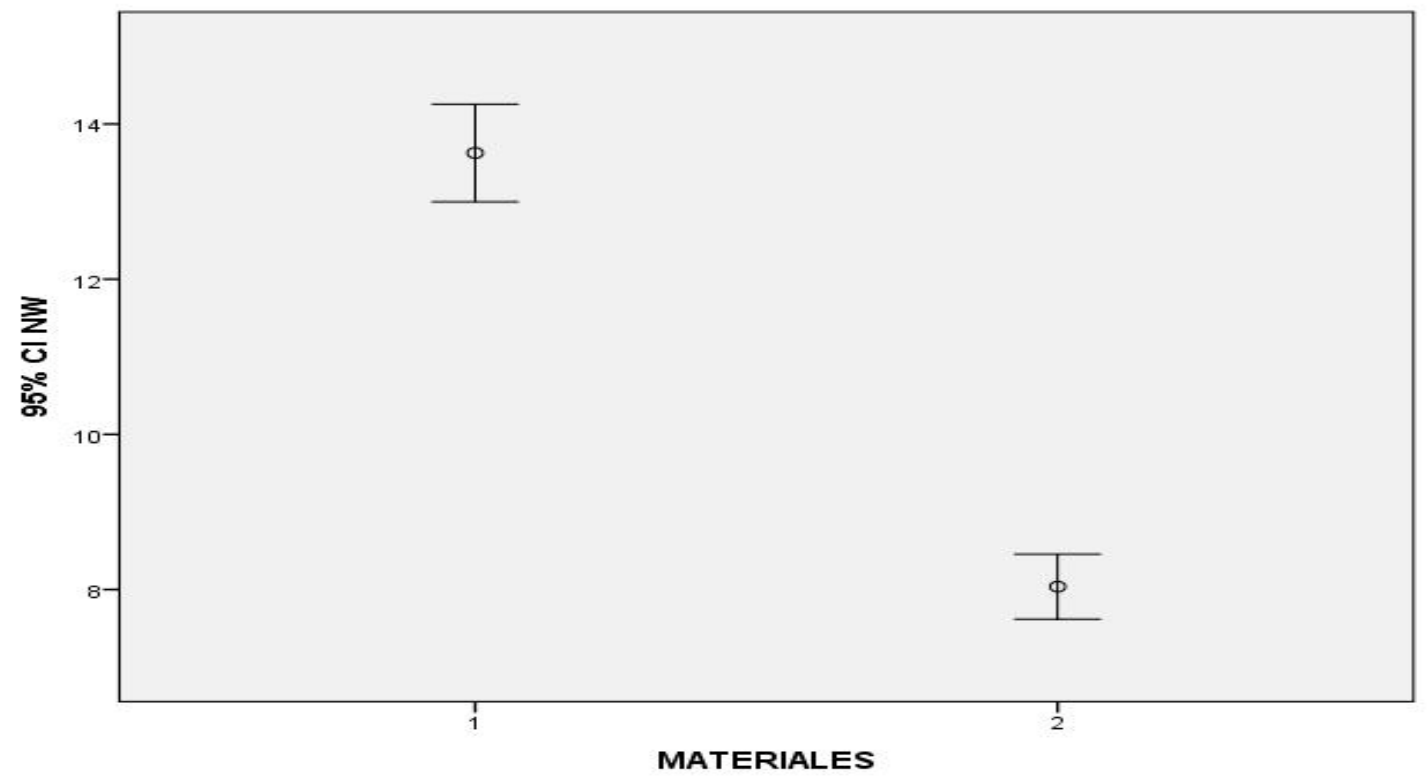

Diagram 3. mean analyzes between the clasps of material 1 and 2. 
Diagram 3 shows the mean analyzes between the clasps of material 1 and

The results of the independent sample $\mathrm{T}$ test (Table 2) indicate the existence of significant differences $(p<0.001)$ between groups 1 and 2 with a 95\% confidence interval and an alpha error of $5 \%$.

The force of eviction of all the clasps is between 5 and 15 Newtons (500g and $1.5 \mathrm{~kg}$ ).

There are two clasps that are broken by fatigue, probably due to the readjustment suffered to adapt them to the abutment, as an existing risk in Co-Cr metal clasps.

We can observe two patterns according to the graphs. In the first 1500 load cycles the holding force rises; this is due to an increase of the friction with the tooth. We pass from a null wear of the enamel (the enamel looks shiny), to a certain wear of it (rough enamel appearance). The force rarely falls below the initial value measured in the first cycle.
If the adjustment is exaggerated we have very high forces up to $25 \mathrm{~N}$, where the enamel wear is exaggerated, and then the extraction force values drop significantly below the initial extraction value. In the tests no PEEK clasp is broken by fatigue.

\section{Insertion Test}

In Diagram 4 and 5 the force in NW required for the insertion of the clasps of materials 1 and 2 is represented by a dot diagram. We also observe in both materials a clasp that reaches higher values of force in NW.

The Pearson correlation coefficient shows the non-existent correlation between the cycles and the NWs in the insertion of the clasps.

In Table 2 we observe a mean of $-14.19 \mathrm{NW}$ of insertion force for the clasps of material 1 and $-5.54 \mathrm{NW}$ for the clasps of material 2.

\section{MATERIALES: 2}

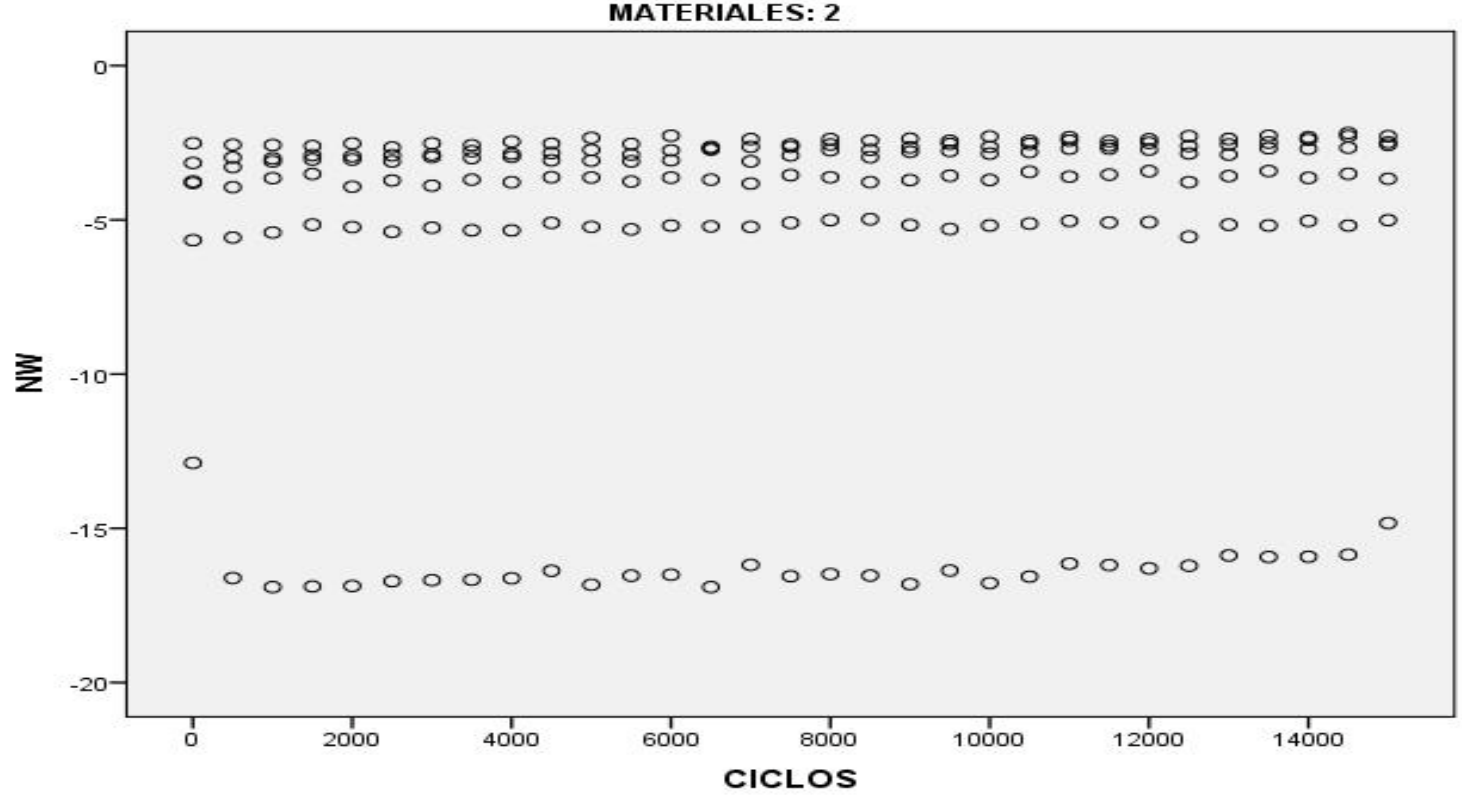




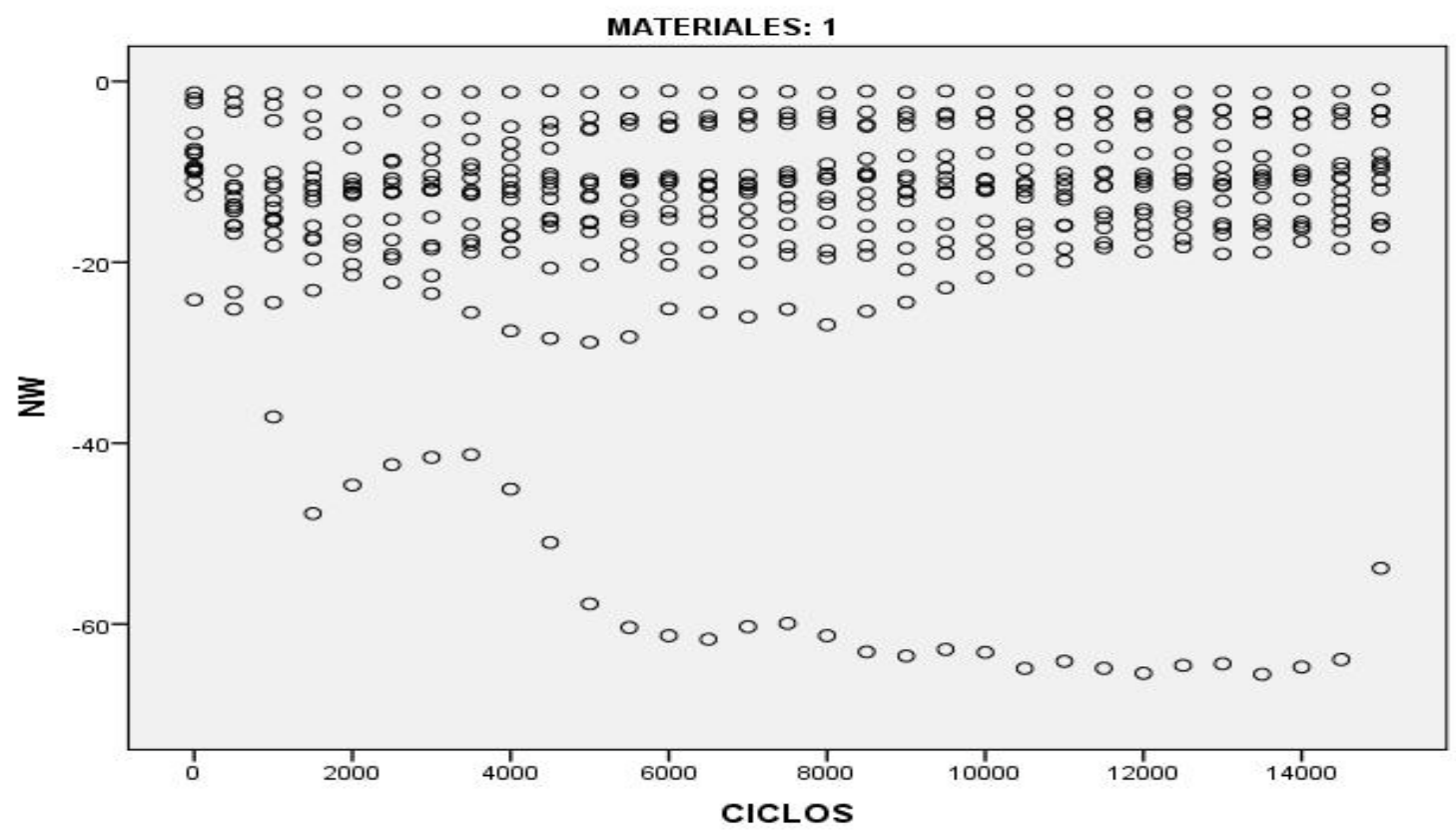

Diagram 4 -5. dot diagram force in $\mathrm{Nw}$ required for insertion of the clasps of materials 1 and 2.

Table 2. means of insertion force of materials 1 and 2.

\begin{tabular}{|c|c|c|c|c|}
\hline Materiales & N & Media & Desv. estándar & Media de error estándar \\
\hline NW 1 & 465 & $-14,19$ & 12,821 &, 595 \\
2 & 186 & $-5,4$ & 4,927 &, 361 \\
\hline
\end{tabular}

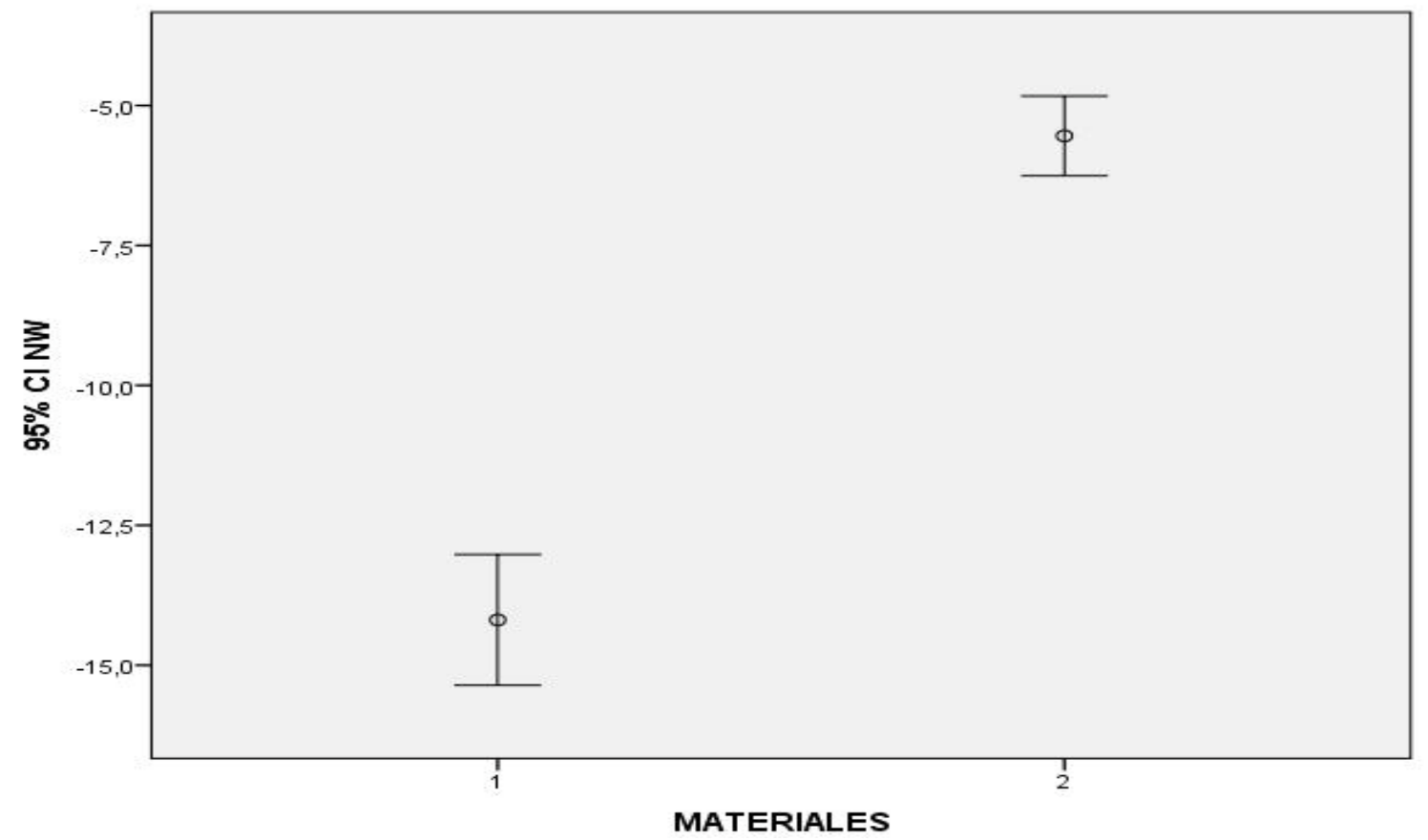

Diagram 6. desinsertion mean analyzes between the clasps of material 1 and 2 
Diagram 6 represents the analysis of means between the clasps of material 1 and 2.

As in the removal test, there are also significant differences ( $p<0.001$ ) between the clasps of material 1 and those of material 2, measuring with a 95\% confidence interval and an alpha error of 5\%.

\section{Discussion}

The results obtained in this in vitro study reinforce the hypothesis that the retention force of the Co-Cr clasps and the retention force of the PEEK clasps are different. Based on the data obtained in the present investigation, the retention forces of the PEEK clasps show values clearly inferior to those of Co-Cr alloy, although clearly valid for their clinical use. We have values between 5 and $8 \mathrm{~N}$ in the clasps of PEEK, only a clasp excels reaching values of force up to $15 N W$.

According to Tannous et al., the differences observed in the retention forces are probably due to the different modulus of elasticity of the materials (Co-Cr and PEEK). Thermoplastic resins such as PEEK have a modulus of elasticity of 4GPa very similar to cortical bone (18GPa), while $\mathrm{Cr}-\mathrm{Co}$ has a much higher modulus of elasticity (230GPa). Thus, the greater modulus of elasticity of the material means the greater retention force. Another advantage of PEEK is its constant homogeneity, its easy polishing, its low affinity for the plaque and its low tendency to discoloration [3].

According to studies by Turner et al. and Arda et al., The low modulus of elasticity of thermoplastic resins (4GPa, PEEK) makes these resins have a higher flexibility compared to the Co-Cr alloy (211GPa). Although the tensile strength of Co-Cr (880MPa) is much higher than that of PEEK (97MPa), we can design the clasps of thermoplastic resins that reduce traumatic overload on the abutment tooth, and still have the sufficient retention force for clinical use. [4, 5] The study by Takabayashi et al. also observes the same advantage of flexibility in prostheses with non-metallic clasps. Prostheses with clasps made with thermoplastic resins provide sufficient retention to the remaining teeth, without exerting excessive local pressure on them. In any case, the design is very important, taking into account the displacement of the soft tissue. [29]

Zoidis et al. note that the modulus of elasticity of PEEK (4GPa) is similar to that of cortical bone (18GPa), so this material can reduce the stress transmitted to the abutment tooth.

In several studies, such as that of Tarek et al.,we conclude that the clasps made with thermoplastic resins have sufficient retention for their clinical use, provided they are of the proper thickness and design. [27]

Tannous et al., in their study concludes that the flexibility of the clasp depends on the section, length and thickness of the material, since the more flexible the less retention [3].

PEEK clasps need a greater diameter to achieve a retention force accepted for clinical use. The PEEK elasticity modolus provides this material more flexibility. So we have to increase the section of the clasp in order to have sufficient retention forces. Although the retention forces of PEEK clasps will be always smaller. If we would make PEEK clasps with de same section like Co-Cr clasps, this would have retention forces unacceptable for clinical use according the study of Tannous et al. Turner et al. examined the flexible properties of the POM, where they determined that the clasps of this thermoplastic resin should be about $5 \mathrm{~mm}$ shorter and with a larger sectional section diameter $(1.4 \mathrm{~mm})$, in order to have a Co-Cr clasp strength of $1 \mathrm{~mm}$ in diameter. [3] According to Arda and Arikan, although the Co-Cr clasps exhibit deformation and not the clasps of acetalic resins, the retention force of the Co-Cr clasps after their deformation remains higher than that of the acetal clasps, although these latest requirements less force of insertion and removal. [4] In our study, PEEK clasps with a larger diameter $(3 \mathrm{~mm})$ were produced than Co-Cr clasps $(1.5 \mathrm{~mm})$, and we confirmed with our study that with larger diameters PEEK clasps, although with lower retention forces.

Previous studies show how the fatigue strength of $\mathrm{Co}-\mathrm{Cr}$ clasps concludes with the loss of retention because of the permanent deformation of the metal. In our study, two Co-Cr clasps were fractured by fatigue and also certainly the deformation suffered by the adjustment suffered when the teeth were re-fitted once they had been cast. Instead of PEEK clasps we do not break any.

According to Bauer et al. the method chosen for the making of the clasps has a great influence. By realizing milled clasps with CAD-CAM system superior values of retention force of up to $8,6 \mathrm{NW}$ are reached. [28]

\section{Conclusions}

The objective of this study was to examine the clasps of PEEK for removable dental prostheses compared with the Co-Cr clasps. Taking into account the limitations of this study, we can conclude that the use of PEEK non-metallic clasps reaches retention forces between 5 and $8 \mathrm{NW}$, totally acceptable for clinical use. However, we can assure that with the correct clinical application we can use PEEK clasps with a better esthetics than Co-Cr clasps. As well, we can observe limitations of the study because it is integrated in an in vitro assay within a rigid system. In the oral cavity the tooth is "cushioned" by the periodontal ligament. Also, it is necessary to take into account the way of insertion and removal of the prostheses that would have the patient. Further studies would be necessary, and if possible studies with patients.

\section{REFERENCES}

[1] Kim D., Park C., Yi Y., Cho L. (2004). Comparision of cast 
Ti-Ni alloy clasp retention with conventional removable partial denture clasps. J Prosthet Dent 91:374-82.

[2] Takabayashi Y. (2010). Characteristics of denture thermoplastic resins for non-metal clasp dentures. Dent Mater 29(4):353-361.

[3] Tannous F., Steiner M., Shahin R., Kern M. (2012). Retentive forces and fatigue resistance of thermoplastic resin clasps. Dent Mater 28:273-278.

[4] Arda T., Arikan A. (2005). An in vitro comparision of retentive force and deformation of acetal resin and cobalt-chromium clasps. J Prosthet Dent 94:267-74.

[5] Turner J.W., Radford D., Sherriff M., (1999). Flexural properties and surface finishing of acetal resin denture clasps. J Proshod 8:188-195.

[6] Klutz S.M., Devine J.N. (2007). PEEK biomaterials in trauma, orthopedic, and spinal implants. Biomaterials 28:4845-4869.

[7] Mahmoud A., Wakbayashi N., Takahashi H., Ohyama T. (2005). Deflection fatigue of Ti-6Al-7Nb, Co-Cr, and gold alloy cast clasps. J Prosthet Dent 93:183-8.

[8] Cheng H., Xu M., Zhang H., Wu W. Zheng M., Li X. (2010). Cyclic fatigue properties of cobalt-chromium alloy clasps for partial removable dental prostheses. J Proshtet Dent 1004:389-396.

[9] Vallittu P.K., Kokkonen M (1995). Deflection fatigue of coblat-chromium, titanimum, and gold alloy cast denture clasp. J Prosthet Dent 74:412-9

[10] Davenport J.C., Basker R.M., Heath J.R., Ralph J.F., Glantz P.O., Hammond P. (2001). Clasp design. British Dent Journal 190:71-81.

[11] Bayer S., Komor N., Kramer A., Albrecht D., Mericske-Stern R., Enkling N. (2012) Retention force of plastic clips on implant bars: a randomized controlled treal. Clinic Oral Implants Res 23:1377-1384.

[12] Donovan Te, Cho GC. (2003) Esthetic considerations with removable partial dentures. J calig Dent ASS 31:551-557.

[13] Donovan TE, Derbabian K., Kaneko L., Wright R. (2001) Esthetic considerations in removable prosthodontics. J Esthet Rest Dent. 13:241-253.

[14] Fitton JS., Davies EK., Howlett JA., Pearson GJ.,(1994). The physical properties of a polyacetal denture resin. Clinic Mater. $17: 125-129$.

[15] Osada H., Shimpo H., Hayakawa T., Ohkubo C. (2013). Influence of thickness and undercut of thermoplastic resin clasps on retentive force. Dent Mter J. 32:381-389.

[16] Rodrigues RC., Ribeiro RF., de Matos Mda G., Bezzon OL. (2002). Comparative study of circumferencial clasp retention force for titanium and cobalt-chromium removable partial dentures. J Prosthet Dent. 88:290-296.

[17] Stawarczyk B., Beuer F., Wimmer T. (2013). Polyetheretherketone- a suitable material for fixed dental prostheses? J Biomed Mater Res Part B. 101:1209-1216.
[18] Sarot JR, Contar CM., Cruz AC., de Souza Magini R. (2010). Evaluation of the stress distribution i CFR-PEEK dental implants by the three-dimensional finite element method. J Mater Sc Med. 21:2079-2085.

[19] Sato Y., Abe Y., Yuasa Y., Akagawa Y. (1997) Effect of friction coefficient in Ackers clasp retention. J Prosthet Dent. 28: 598-600.

[20] Sato Y., Tsuga K., Abe Y., Asahara S., Akagawa Y. (2001). Analysis of stiffness and stress in I-bar clasps. J Oral Rehab. 28:596-600.

[21] Souza JE., Silva NR., Coelho PG., Zavanelli AC., Ferracioli RC., Zavanelli RA. (2011). Retenion strenght of cobalt chromium vs. nickel-chromium titanium vs. CP titanium in a cast framework association of removable partial overdenture. J Contemp Dent Prac. 12:179-186.

[22] Fueki k. et al. (2014). Clinical application of removable partial dentures -Part I: definition and indication of non-metal clasp dentures. J of Prost Res. 58:3-10.

[23] Fueki k. et al. (2014). Clinical application of removable partial dentures -Part I: material properties and clinical features of non-metal clasp dentures. J of Prost Res. 58:71-84.

[24] Sando L., Faur N., Bortun C. (2007). Finite element stress analysis and fatigue behavior of cast circumferential clasps. The J of Prost Dent. 97:39-44.

[25] Tokue A., Hayakawa T., Ohkubo C. (2013).Fatigue resistance and retentive force of cast clasps treated by shot peening. $\mathrm{J}$ of Prost Res. 57:186-194.

[26] Kawara M., Iwata Y., Iwasaki M., Komoda Y., Iida T., Asano T., Komiyama O. (2014). Scratch test of thermoplastic denture base resins for non-metal clasp dentures. $\mathrm{J}$ of Prost Res. 58:35-40.

[27] Tarek M., Osama A. B., Magdy M. B. (2013). Comparision between Acetal Resin and Cobalt-Chromium Removable Partial Denture Clasp Retention: An in vitro Study. J od Prost Res. 3:50-56.

[28] Bauer S., Eichberger M., Stawarczyk B., Fuerzas de retención de los revendedores de prótesis parciales de resina basadas en PEEK. Quintessence Técnica. 2: 326-331.

[29] Trifkovi B. (2013). Finite element analysis in defining the optimal shape and safety factor of retentive clasp arms of a removable partial denture. Vojnosanit Pregl. 70(11): 9991005.

[30] Takabayashi Y., Hamanaka I., Shimizu U. (2012). Effect of thermal shock on mechanical properties of injected-molded thermoplastic base resins. Acta Odont Scand. 70:297-302.

[31] Donovan T.E., Derbabien K., Kaneko L., Wright R. (2001). Esthetic considerations in removable prosthodontics. J of Esthet Restor Dent. 13:24

[32] Mohamed T., Barak O.A., Badawy M.M. (2013) Comparision between Acetal Resin and Cobalt-Chromium Removable Partial Denture Clasp Retention: An in vitro Study. J Prosthodont Restor Dent. 13:50-56. 